\title{
Die vielleicht älteste europäische Darstellung einer Kamelie
}

\author{
JÖRG DÄHNHARDT
}

\begin{abstract}
A songbook from Portugal (early 16. century) is ornamented with flowers that are reminescent of camellias. It is very difficult to verify that they really represent camellias. It is possible, that mariners brought camellias from Asia to Lissabon. The songbook might show one of the most ancient european drawings of a camellia flower.
\end{abstract}

\section{Zusammenfassung}

Ein portugiesisches Gesangbuch aus dem frühen 16. Jh. ist mit Blüten-Illustrationen verziert, die sehr an Kamelien erinnern. Portugiesische Seefahrer hätten jedenfalls schon damals Kamelien mitgebracht haben können. Das Gesangbuch könnte also eine der ältesten europäischen Darstellungen einer Kamelien-Blüte enthalten.

\section{Ein altes Gesangbuch mit Kamelien-Blüten?}

Im Deutsch-Portugiesischen Museum bei Lissabon liegt ein portugiesisches Gesangbuch aus der Früh-Renaissance. Es umfasst 116 Seiten Ziegenpergament, die mit Noten und dem Haupttext von Kirchenliedern beschrieben sind. Zudem enthält es fünf sehr reich verzierte Schmuck-Seiten. Auf vier dieser reich verzierten Seiten sind in zentraler Position Blüten mit Merkmalen einer Kamelie dargestellt.

Dank des Familienwappens kann das Buch als Auftragsarbeit (um ca. 1520) für den portugiesischen Adeligen Lopo Fernandes PaCheCO angesehen werden. Der Illustrator war kein geringerer als ANTONIO DA HOLLANDA, ein Lissabonner Hof-Illustrator, der auch Adelsbriefe im Auftrag des Königs schuf, wie im Deutsch-Portugiesischen Museum zu sehen ist. Zudem illustrierte er die „Generalogia Iluminada do Infante D. FERNANDO", die im British Museum in London eingesehen werden kann.

Zwischen der rein floralen Verzierung am Blattrand, die durch ihre leuchtenden Farben und die Verwendung von Blattgold besticht, sind Paradiesvögel und Pfauen zu erkennen. Diese Motive sind ebenfalls wichtige Hinweise für den Entstehungs-Zeitraum des Buches. Denn im Konzil von Trento (1548) hatte der Papst die Darstellung von Symbolen der Wiedergeburt

Abb. 1: Eine Seite aus dem Gesangbuch. verboten. Er beanspruchte das Recht auf Wiedergeburt exklusiv für die Römisch-Katholische Kirche. Pfau oder Phoenix waren derartige Symbole, die zuvor von den Urchristen benutzt worden waren. Somit dürfte das Buch vor dem Konzil entstanden sein.

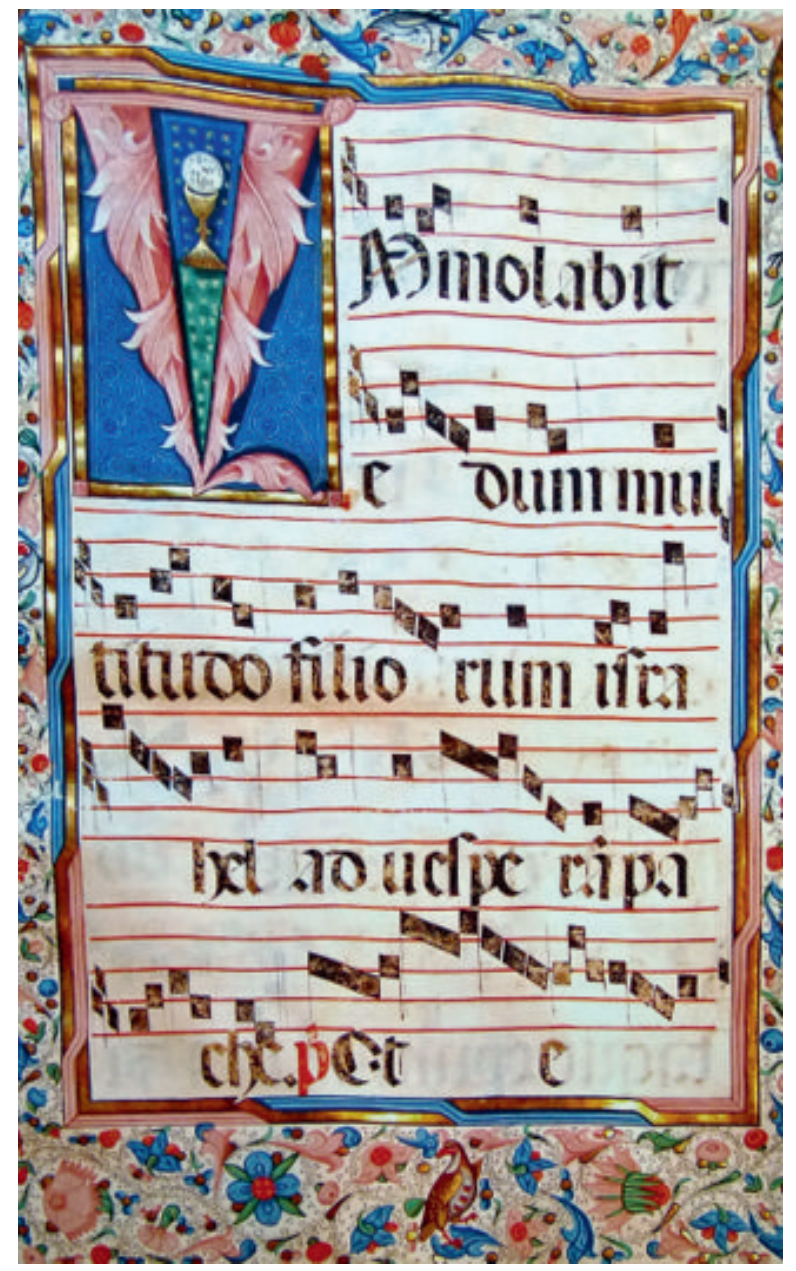



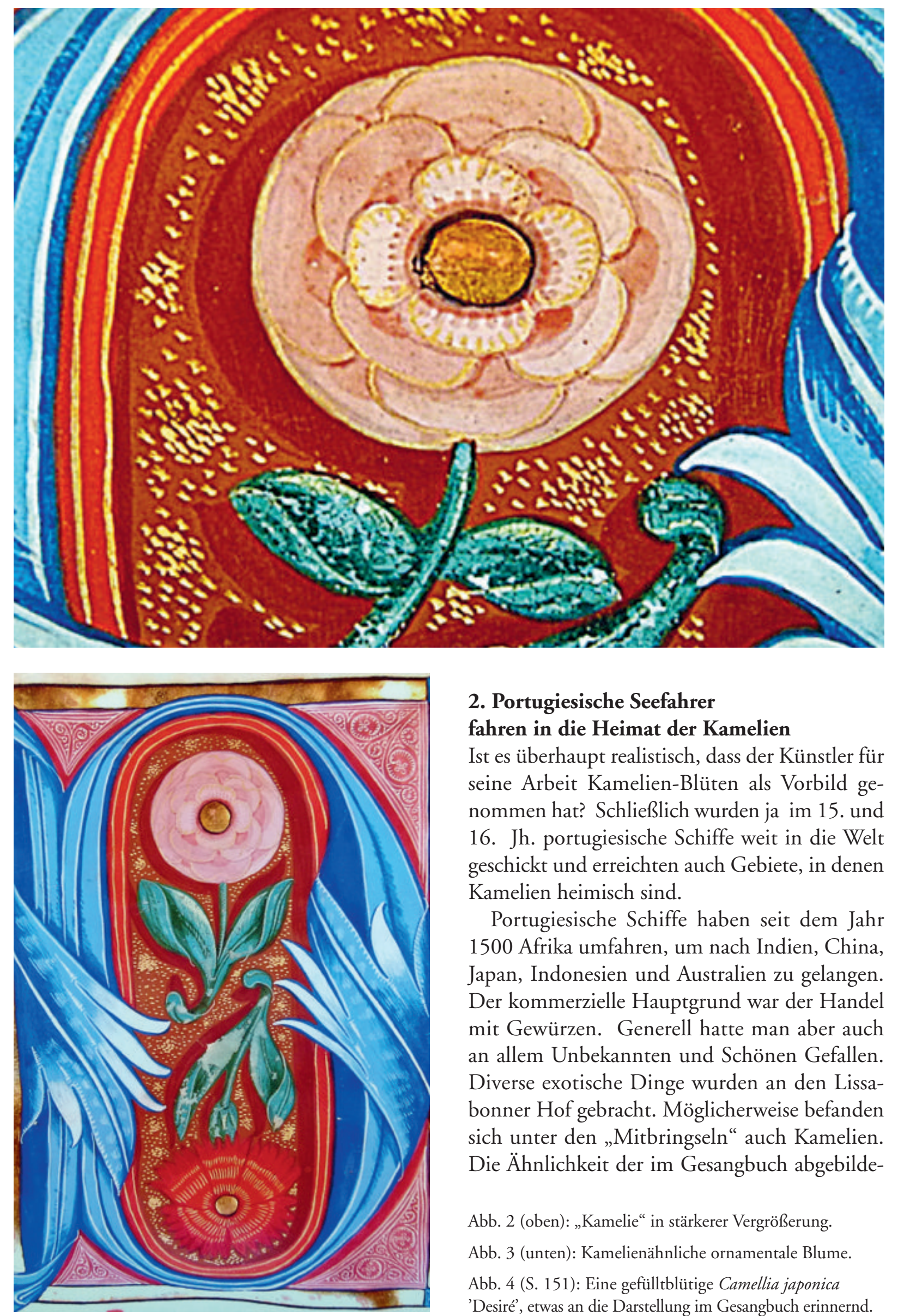

2. Portugiesische Seefahrer

fahren in die Heimat der Kamelien

Ist es überhaupt realistisch, dass der Künstler für seine Arbeit Kamelien-Blüten als Vorbild genommen hat? Schließlich wurden ja im 15. und 16. Jh. portugiesische Schiffe weit in die Welt geschickt und erreichten auch Gebiete, in denen Kamelien heimisch sind.

Portugiesische Schiffe haben seit dem Jahr 1500 Afrika umfahren, um nach Indien, China, Japan, Indonesien und Australien zu gelangen. Der kommerzielle Hauptgrund war der Handel mit Gewürzen. Generell hatte man aber auch an allem Unbekannten und Schönen Gefallen. Diverse exotische Dinge wurden an den Lissabonner Hof gebracht. Möglicherweise befanden sich unter den „Mitbringseln“ auch Kamelien. Die Ähnlichkeit der im Gesangbuch abgebilde-

Abb. 2 (oben): „Kamelie“ in stärkerer Vergrößerung.

Abb. 3 (unten): Kamelienähnliche ornamentale Blume.

Abb. 4 (S. 151): Eine gefülltblütige Camellia japonica

'Desiré', etwas an die Darstellung im Gesangbuch erinnernd. 


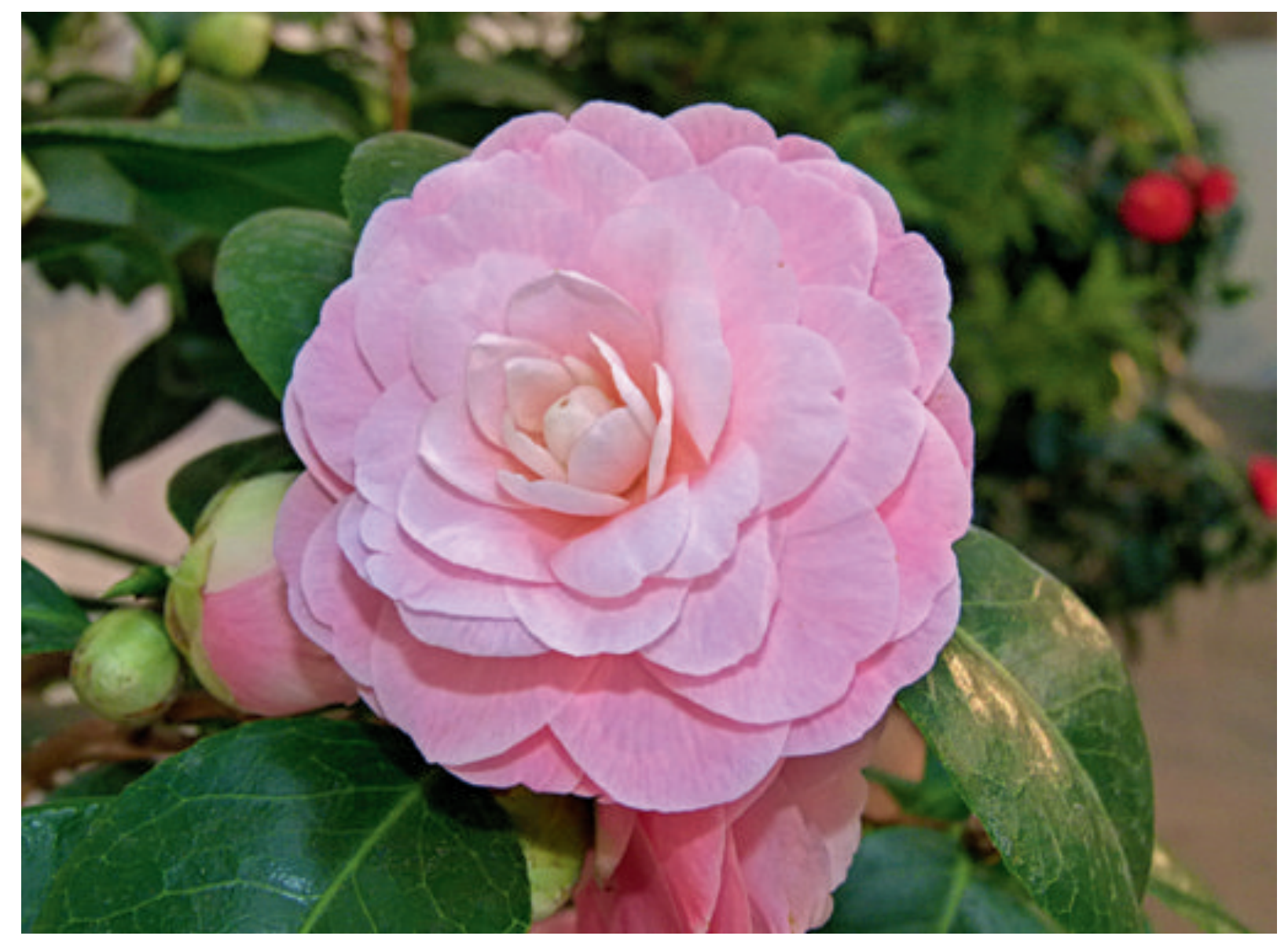

ten Blüten mit Kamelien ist verblüffend. Allerdings darf nicht vergessen werden, dass es sich hier um eine florale Verzierung und nicht um eine exakte botanische Darstellung handelt.

\section{Portugiesen erkunden die Welt}

1498: VASCO DA GAMA erreicht Indien

1502: Pedro Álvares Cabral erobert die Indische Küste um Cochim und Kerala

1511: ANTÓNIO DE ABREU erreicht Sumatra, Java und Malaysia

1515: Jorge AlVARES erreicht China

1516: DuARTE COELHO erreicht das Königreich Bengalen, Siam und Vietnam

1517: Portugiesen landen in der chinesischen Provinz Guangdong

1517: Portugiesen landen in Ost-Timor

1517: Frenao Peres de Andrade bereist China

1537-1558: Frenao MENDEs Pinto bereist Indien, Vietnam und China

1543: FRENAO MENDES PiNTO kommt nach Japan und führt dort das Gewehr und die Schraube ein 